\title{
Das sich verschenkende Lachen Gottes
}

Pierre Bühler

Kann man überhaupt vom Lachen Gottes sprechen? Sowohl in der Bibel als auch in der theologischen Tradition fallen die Aussagen dazu recht spärlich aus. Deshalb kommt man schnell in die Gefahr des Spekulierens: lacht Gott, kann er es überhaupt, darf er es, und wenn ja, wie lacht er? Bei solchem Nachdenken über das göttliche Lachen bringen wir dann vielleicht Gott erst recht zum Lachen - zum Lachen darüber, wie wir uns sein Lachen vorstellen! "Der Mensch denkt, Gott lacht», so heisse gemäss Milan Kundera ein schönes jüdisches Sprichwort ${ }^{1}$.

Unser Thema ist also nicht ungefährlich. Einige befürchten bereits, sich mit ihm vor derWelt, vor der Öffentlichkeit lächerlich zu machen! Viel schlimmer noch wäre aber, sich damit vor Gott lächerlich zu machen! Oder vielleicht doch nicht? Weil wir in vielem vor Gott bereits lächerlich sind, manchmal gerade in unserem allzu grossen Ernst, in unserem Bierernst?

Deshalb dürfen wir ruhig an diesem Thema etwas weiter arbeiten. Freilich muss der Gefahr der reinen Spekulation entgangen werden, und das tut man am besten, indem man sich im Sinne der reformatorischen cognitio Dei et hominis daran erinnert, dass man nur so von Gott reden kann, dass man zugleich vom Menschen redet. Für unser Thema heisst das: das Lachen Gottes ist immer mit dem Lachen des Menschen verbunden.

\section{Das Lachen - Proprium des Menschen}

Eine lange philosophische Tradition, bei Aristoteles einsetzend, definiert den Menschen durch seine Lachfähigkeit. Was zunächst bei Aristoteles als eine rein physiologische Eigenschaft wahrgenommen wird, verbunden mit dem menschlichen Zwerchfell, und dann im Mittelalter als blosses Beispiel der Logik fungiert, bekommt in der Renaissance eine humanistische Dimension. So etwa im Lachen der Riesen Gargantua und Pantagruel, mit dem Rabelais gegen die "Agelasten" kämpft, wie er sie vom Griechischen her nennt, die "Nicht-Lacher", die Menschen, die keinen Sinn für Humor haben. Dazu bemerkt Kundera, er stelle sich gerne vor, wie François Rabelais «eines Tages Gottes Lachen hörte und so die Idee des ersten grossen europäischen Romans geboren wurde" . 
Wenn also das Lachen Proprium des Menschen ist, wie die philosophische Tradition meint, dürfte das, so Kunderas Vermutung in Hinsicht auf Rabelais, auch mit dem Lachen Gottes zusammenhängen. Das Lachen wäre dann nicht nur Proprium des Menschen, sondern ebenso Proprium Gottes, und damit wäre das menschliche Lachen wie ein geschöpfliches Ebenbild des göttlichen Lachens. Oder sollte vielmehr umgekehrt argumentiert werden: Was Proprium des Menschen ist, sei gerade nicht Proprium Gottes, sondern sündhaftesVerhalten, das den radikalen Unterschied zwischen Gott und Mensch markiert, so dass man Gott als den grossen "Agelasten» bezeichnen müsste, auf den sich alle menschlichen "Agelasten" beziehen dürften? Lachen wäre dann die eigentliche Ursünde, wie auch der alte Bibliothekar im Namen der Rose von Umberto Eco argumentiert.

Weil ich lieber bei Rabelais als bei den "Agelasten" verweile, tendiere ich zur ersten Hypothese. Vielleicht aber greift die Alternative auch zu kurz, weil sie nicht die Tatsache in Rechnung stellt, dass das Proprium des Menschen sehr ambivalent sein kann.

\section{Das Lachen - menschlich oder unmenschlich?}

Oft in der Tradition wurde das Lachen verurteilt, weil es verachtend, erniedrigend wirkt. Man spottet und macht sich lustig, indem man den anderen, über den man lacht, «verlächerlicht). So sagte Hobbes, das Lachen entstehe immer aus einem Gefühl der Überlegenheit. Dieses "degradierende" Lachen gibt es unter Menschen natürlich immer wieder, und es kann auch schnell sehr unmenschlich werden. Demgegenüber könnte man ein Lachen betonen, das dem Proprium des Menschlichen besser entspricht: ein Lachen, in dem mir geschenkt wird, die Spannungen, die Widersprüchlichkeiten, die Diskordanzen des menschlichen Lebens in befreiendem Licht wahrzunehmen, so dass ich herzhaft darüber lachen kann, dabei sowohl über andere als auch über mich selbst lachend, weil wir alle davon betroffen werden. Dieses «Diskordanzlachen» schafft zwar auch Distanz, aber nicht im Sinne einer degradierenden 'Verlächerlichung), sondern einer schöpferischen Freiheit und Menschlichkeit im Umgang mit den Dingen des Lebens.

So könnten wir sagen: Wo degradierendes Lachen stattfindet, ist Sünde im Spiel. Wo hingegen dem Menschen ein Diskordanzlachen widerfährt, kommt in seinem menschlichen Lachen auch etwas vom göttlichen Lachen zum Zuge. Oder noch stärker: solches befreiendes Lachen wird dem Menschen vom göttlichen Lachen her zuteil. 
Eine solche Unterscheidung führt uns dazu, das vorhin formulierte schöpfungstheologische Modell etwas zu korrigieren. Nicht jedes Lachen ist bereits gottebenbildlich, denn das menschliche Lachen steht im Zeichen der Ambivalenz der Sündhaftigkeit. Lachen als degradierendes Lachen degradiert sündhaft die Betroffenen, sowohl den Lachenden als auch den Verlachten, und sogar das Lachen selbst. Ihm gegenüber wirkt das göttliche Lachen heilend und klärend: es wird dort konkret erfahrbar, wo es das menschliche Lachen aus der Degradierung hinaus in die Diskordanz hinein befreit. Ist das alles nun nicht reine Spekulation?

\section{Risus passivus}

Nicht einfach müssige Spekulation sind unsere Überlegungen, wenn es gelingt, sie als Auslegung der Glaubenserfahrung wahrzunehmen. Aussagen über das Lachen Gottes sind Glaubensaussagen, die zum Ausdruck bringen, wie ich glaubend mein Lachen vor Gott verstehe.

Dieser Aufgabe möchte ich mich stellen, indem ich versuche, auf eine Frage von Max Frisch zu antworten, die er in seinem Tagebuch 1966-1971 an seinen Leser richtet: "Gesetzt den Fall, Sie glauben an einen Gott:kennen Sie ein Anzeichen dafür, dass er Humor hat?» Meine Antwort wäre folgende: Mein einziges Anzeichen dafür, dass der Gott, an den ich glaube, Humor hat, ist die Erfahrung, dass ich nicht umhin komme, wenn mir Lachen zuteil wird, dieses Lachen auf ihn zu beziehen und es als sein Geschenk in Empfang zu nehmen. Ich komme nicht umhin, das Geschenk des Lachens im Sinne eines befreienden Lachens als Gottes Geschenk zu verstehen.

Diese Glaubenserfahrung könnte man deshalb ganz im Sinne des Rechtfertigungsglaubens formulieren. Die Gerechtigkeit Gottes, so betonten es die Reformatoren, ist nicht die Gerechtigkeit, durch die Gott gerecht ist und von mir Gerechtigkeit verlangt, sondern die Gerechtigkeit, durch die Gott mich gerecht macht. Ganz ähnlich gilt auch dieser "genitivus auctoris» für das Lachen Gottes: Das Lachen Gottes ist das Lachen, durch das er mich lachen lässt. Wie seine Gerechtigkeit iustitia passiva ist, ist auch sein Lachen risus passivus. Das Lachen Gottes ist das sich verschenkende Lachen Gottes, das deshalb «aus Glauben zu Glauben» ist (Röm 1,17). Anzeichen des Humors Gottes ist also diese Glaubenserfahrung, dass er mich nie zum «Agelasten» werden lässt. Im Sinne eines kühnen Rückschlusses kann ich glaubend vermuten, dass er sich so um mein Lachen bemüht, weil er selbst nicht zu den "Agelasten» gehört. 
Was heisst das nun für das menschliche Leben konkret?

\section{Das Lachen als heilsame Verfremdung}

Lachen eröffnet befreiende Distanz, haben wir gesagt, die es erlaubt, Diskordanzen, Spannungen wahrzunehmen, um an ihnen kreativ zu arbeiten. In diesem Sinne könnte man von einer heilsamen Verfrem-dung sprechen, der wir uns immer wieder dürfen aussetzen lassen. Im Versuch, die Dinge in den Griff zu bekommen, das Leben und seine Aufgaben zu meistern, alles zu beherrschen, gehen wir ohne Distanz vor. Verfremdung hingegen stört unsere Beherrschungsversuche und lässt uns aus der Distanz einüben, dass wir auf das Beschenktwerden angewiesen sind.

Das gilt auch in Hinsicht auf unsere Gottesbeziehung: das Lachen Gottes schafft die Verfremdung, die mir immer wieder bewusst werden lässt, dass ich Gott nicht in den Griff bekomme, dass er nicht einfach verfügbar ist, sondern sich meiner Beherrschung entzieht, um sich mir immer wieder unter überraschenden Aspekten zu zeigen. Damit vollzieht sich aber auch eine Verfremdung mir und meinem Versuch gegenüber, mich selbst in den Griff zu bekommen: Das Lachen Gottes versetzt mich ausserhalb meiner selbst und befreit mich deshalb zu einem neuen Umgang mit mir selbst. Erst von dorther kann ich auch meinem Proprium, dem Lachen, gerecht werden und werde so im Lachen durch Glauben allein zum eigentlich wahren, geschöpflichen Menschen.

\section{Sind Theologen «Agelasten»?}

Gehört somit das Lachen Gottes grundlegend zur Glaubenserfahrung und bezieht sich Theologie auf eben diese Glaubenserfahrung, so sollten Theologen nichts mit "Agelasten» zu tun haben. Die Erfahrung bestätigt diese Folgerung leider nicht uneingeschränkt, und Rabelais hatte die Theologen, die er kannte, eher auf der Seite der "Agelasten» angesiedelt. Für einmal möchte ich mich hier von ihm distanzieren und etwas kühn meine Hoffnung zum Ausdruck bringen, indem ich Kundera frei variiere: "Mir gefällt der Gedanke, dass die Kunst der Theologie als Echo auf Gottes Lachen zur Welt kam.»

1 Die Kunst des Romans. Essay, München/Wien 1987, S. 166. Kundera fügt hinzu: «Mir gefällt der Gedanke, daß die Kunst des Romans als Echo auf Gottes Lachen zur Welt kam.»

— Dr. Pierre Bühler ist Professor für Systematische Theologie an der Theologischen Fakultät der Universität Zürich. 